\title{
Impaired Erythrocyte Filterability of Spontaneously Hypertensive Rats: Investigation by Nickel Mesh Filtration Technique
}

Kyoko Ariyoshi, MD; Toru Maruyama, MD*; Keita Odashiro, MD; Koichi Akashi, MD; Takehiko Fujino, MD**; Nobuhiro Uyesaka, MD ${ }^{\dagger}$

\begin{abstract}
Background: Deformability of erythrocytes plays a key role in the impairment of the microcirculation in hypertension. However, erythrocyte deformability in spontaneously hypertensive rats (SHR) during development of hypertension has not been fully investigated so far.
\end{abstract}

Methods and Results: Erythrocyte filterability (whole cell deformability) was investigated in relation to blood pressure measured by the tail-cuff method in SHR and age-matched Wistar-Kyoto rats (WKY), using a highly sensitive and reproducible nickel mesh filtration technique. Impaired erythrocyte filterability was marked $(37.0 \pm 17.5 \%)$ in prehypertensive young SHR (7 weeks of age) and sustained $(51.6 \pm 13.3 \%)$ in hypertensive mature SHR (18 weeks of age), when compared with that of age-matched WKY $(62.1 \pm 7.2 \%$ in 7 weeks of age, $\mathrm{P}<0.005$, and $71.1 \pm 3.9 \%$ in 18 weeks of age, $\mathrm{P}<0.005$, respectively). This impairment in SHR could not be explained by the mean corpuscular volume or mean corpuscular hemoglobin concentration of erythrocytes, but the erythrocyte count was significantly $(\mathrm{P}<0.005)$ greater in SHR than in the age-matched WKY.

Conclusions: Although the precise mechanisms remain to be elucidated, markedly impaired erythrocyte filterability in SHR is considered to contribute to the development and maintenance of genetic hypertension. (Circ $J$ 2010; 74: 129-136)

Key Words: Erythrocytes; Genetic hypertension; Microcirculation; Rheology

$\mathbf{H}$ ypertension is 1 of the greatest causes of cardiac events in many countries. In this field, hemorheology has been attracting less attention relative to vascular medicine. However, the deformability of erythrocytes, a major concept in hemorheology, plays a key role in the impaired microcirculation of hypertension. ${ }^{1}$ The concept of erythrocyte deformability has no strict definition as a physical quantity, so its evaluation depends on measurement techniques, and the relative sensitivities of these techniques are influenced by various factors that comprise deformability. Because the filtration of erythrocytes through artificial narrow pores is relevant to microcirculation in vivo, filtration techniques are the most widely used to assess the physiological deformation of intact erythrocytes in cases where deformation in vivo involves bending. Erythrocyte deformability is quantified as erythrocyte filterability (whole cell deformability) using a gravity-based nickel mesh filtration technique, ${ }^{2-4}$ because the physiological importance and clinical benefit of this technique are evident. ${ }^{5-7}$ Recently, we found that disturbed microcirculation in vivo is closely related to impaired erythrocyte filterability, ${ }^{4}$ as suggested by the Fahraeus-Lindqvist effect. ${ }^{8}$

Spontaneously hypertensive rats (SHR) are an excellent model of human hypertension. ${ }^{9,10}$ Erythrocyte deformability influences whole blood viscosity and microvascular resistance at moderate to high shear rates, so it is a fundamental problem in SHR whether erythrocyte deformability is impaired or not. In fact, increased erythrocyte membrane rigidity has been reported in SHR. ${ }^{11-13}$ Such rheologic abnormalities influence overall blood flow conditions and lead to microvessel occlusion in SHR. ${ }^{14}$ However, information with respect to erythrocyte deformability is extremely limited. ${ }^{15}$ In the present study, erythrocyte filterability was investigated during the development and maintenance of hypertension in SHR and age-matched normotensive Wistar-Kyoto rats (WKY), using a nickel mesh filtration technique.

Received April 14, 2009; revised manuscript received August 20, 2009; accepted September 8, 2009; released online December 2, 2009 Time for primary review: 37 days

Department of Medicine \& Biosystemic Science, Kyushu University, Fukuoka, *Institute of Health Science, Kyushu University, Kasuga,

**Institute of Rheological Function of Foods Co Ltd, Hisayama and 'Department of Physiology, Nippon Medical School, Tokyo, Japan

Mailing address: Toru Maruyama, MD, Institute of Health Science, Kyushu University, 6-1 Kasuga Kohen, Kasuga 816-8580, Japan.

E-mail: maruyama@ihs.kyushu-u.ac.jp

ISSN-1346-9843 doi:10.1253/circj.CJ-09-0252

All rights are reserved to the Japanese Circulation Society. For permissions, please e-mail: cj@j-circ.or.jp 


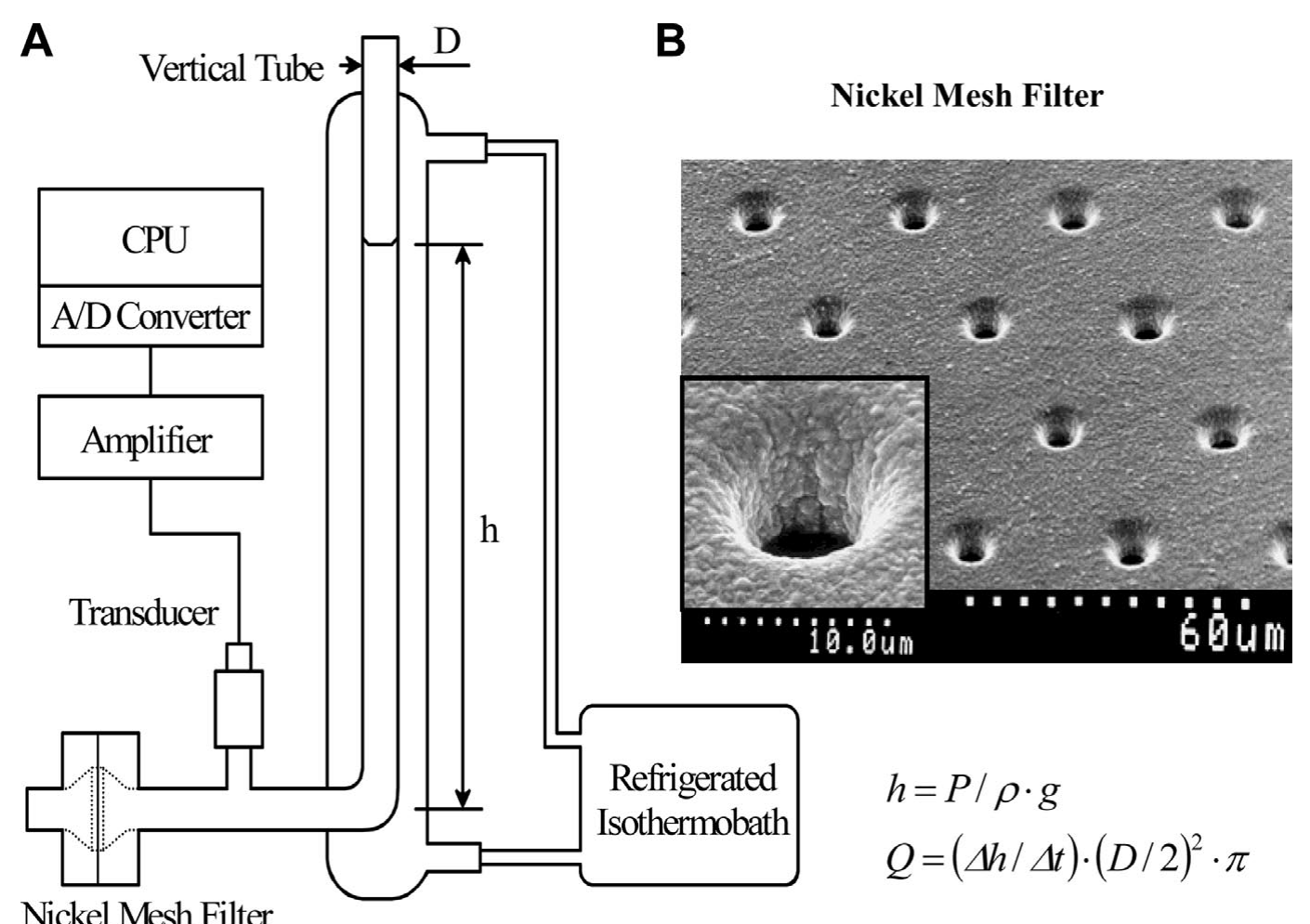

Figure 1. Schematic illustration of the gravity-based nickel mesh filtration system (A) and a scanning electron microscopic photograph of the nickel mesh filter (B). P, pressure $\left(\mathrm{mmH}_{2} \mathrm{O}\right) ; \mathrm{Q}$, flow rates $(\mathrm{ml} / \mathrm{min}) ; \mathrm{h}$, height $(\mathrm{mm}) ; \mathrm{D}$, internal diameter $(\mathrm{mm})$.

\section{Methods}

\section{Animals}

The study design and experimental protocol using male SHR and WKY (Charles River Japan, Tsukuba, Japan) were approved by the internal ethics committee of the Institute of Rheological Function of Foods, Co Ltd (Fukuoka, Japan). According to the literature, ${ }^{13,16}$ we chose to study 3 points in time that correspond to different evolutionary hypertensive stages of SHR: 7 weeks of age, the "prehypertensive stage"; 13 weeks of age, the "accelerated stage"; and 18 weeks of age, the "established stage" of hypertension. Rats were treated according to the National Institutes of Health (NIH) Guide for the Care and Use of Laboratory Animals. Arterial blood pressure (BP: $\mathrm{mmHg}$ ) and pulse rate (PR: beats/min) were measured without sedation by the tail-cuff method using BP-98A (Softron Inc, Tokyo, Japan) every week and $1 \mathrm{~h}$ before humane killing for blood sampling.

\section{Preparation of Erythrocyte Suspensions}

Erythrocyte suspensions were prepared as described elsewhere. ${ }^{3,6}$ The 2 strains of rats were anesthetized by ether (Wako Co Ltd, Osaka, Japan) inhalation and intraperitoneal injection of pentobarbital $(40 \mathrm{mg} / \mathrm{kg}$; Abbott Laboratory, Chicago, IL, USA). Under 12-h fasting conditions, the rats' blood was sampled after laparotomy by puncturing the abdominal aorta using a 21-gauge needle and disposable evacuated syringes (Terumo Japan, Tokyo, Japan) filled with $1 / 10$ volume of $3.8 \%$ trisodium citrate as an anticoagulant. Blood cell counting and hematocrit measurement were carried out using a hemocytometer (Ace Counter, FLC-240A,
Fukuda Denshi Co Ltd, Tokyo, Japan). After centrifugation at $1,300 \times \mathrm{g}$ for $10 \mathrm{~min}$, the plasma and buffy coat were removed and replaced with $\mathrm{N}$-(2-hydroxyethyl)-piperazineN'-2-ethanesulfonic acid (HEPES) sodium salt (HEPES-Na)buffered saline solution (HBS: $\mathrm{NaCl} 141 \mathrm{mmol} / \mathrm{L}$, HEPES-Na $10 \mathrm{mmol} / \mathrm{L})$. The osmolality and $\mathrm{pH}$ of the HBS were $287 \mathrm{mOsm} \cdot \mathrm{kg}^{-1} \cdot \mathrm{H}_{2} \mathrm{O}^{-1}$ and 7.4 , respectively. The osmolality was measured using a freezing point depression type osmometer (Fiske Mark 3 Osmometer, Fiske Associates, MA, USA). The erythrocyte suspension was then washed 3 times by repeated resuspension with $\mathrm{HBS}$ and centrifugation at $800 \times \mathrm{g}, 600 \times \mathrm{g}$ and $500 \times \mathrm{g}$ for $10 \mathrm{~min}$ each. The final hematocrit value of the erythrocyte suspension was adjusted to $2.0 \%$ for subsequent filtration experiments. These procedures were performed within $2 \mathrm{~h}$ of blood sampling to prevent damage to the fragile living erythrocytes.

\section{Erythrocyte Filterability and Shape}

A nickel mesh filter was produced in accordance with our specifications by a photofabrication technique (Dainippon Printing Co Ltd, Tokyo, Japan). We specified an outer diameter of $13 \mathrm{~mm}$, a diameter in filtration area of $8 \mathrm{~mm}$, a thickness of $11 \mu \mathrm{m}$ and an interpore distance of $35 \mu \mathrm{m}$. The pore diameter was exactly $3.88 \mu \mathrm{m}$. The vertical and cylindrical pores were regularly distributed across the filter without branching or coincidence. The pores' entrance had a rounded and smooth transition into the interior of the pore (Figure 1).

Filtration experiments were performed with a gravitybased filtration apparatus (Model NOBU-II, Tsukasa Sokken Co Ltd, Tokyo, Japan). In brief, the hydrostatic pressure (P: $\mathrm{mmH}_{2} \mathrm{O}$ ) vs the drop-time (t: s) curve was obtained during 


\begin{tabular}{|c|c|c|}
\hline Age (weeks) & SHR & $\begin{array}{c}\text { Age-matched } \\
\text { WKY }\end{array}$ \\
\hline \multicolumn{3}{|l|}{ SBP (mmHg) } \\
\hline 7 & $127.3 \pm 14.8$ & $121.3 \pm 12.9$ \\
\hline 13 & $173.5 \pm 14.7^{\#, \star}$ & $141.0 \pm 6.2^{\dagger}$ \\
\hline 18 & $196.7 \pm 16.1^{\# \#, *}$ & $138.3 \pm 10.8$ \\
\hline \multicolumn{3}{|l|}{ MBP $(\mathrm{mmHg})$} \\
\hline 7 & $111.3 \pm 10.2$ & $108.2 \pm 12.9$ \\
\hline 13 & $147.3 \pm 21.1^{\#, \star}$ & $119.7 \pm 11.0$ \\
\hline 18 & $157.1 \pm 19.9^{\# \#, *}$ & $113.0 \pm 10.5$ \\
\hline \multicolumn{3}{|l|}{ DBP (mmHg) } \\
\hline 7 & $96.0 \pm 12.4$ & $91.0 \pm 11.2$ \\
\hline 13 & $121.6 \pm 18.2^{\dagger,+}$ & $93.4 \pm 12.1$ \\
\hline 18 & $139.5 \pm 20.9^{\ddagger, *}$ & $88.3 \pm 13.7$ \\
\hline \multicolumn{3}{|c|}{ Pulse rate (beats/min) } \\
\hline 7 & $393.0 \pm 44.8$ & $367.8 \pm 34.2$ \\
\hline 13 & $376.2 \pm 60.4$ & $348.2 \pm 29.8$ \\
\hline 18 & $342.2 \pm 21.9^{\dagger}$ & $332.3 \pm 30.0^{\dagger}$ \\
\hline
\end{tabular}

Values are expressed as mean $\pm S D$. ${ }^{+} P<0.01$ and ${ }^{*} P<0.005$ for age-matched comparison, and ${ }^{\dagger} \mathrm{P}<0.05, \pm \mathrm{P}<0.01,{ }^{*} \mathrm{P}<0.005$ and ${ }^{\#} \mathrm{P}<0.001$ for comparison between 7 and respective weeks of age within the same strain.

SHR, spontaneously hypertensive rats; WKY, Wistar-Kyoto rats; $\mathrm{DBP}, \mathrm{MBP}$ and SBP, diastolic, mean and systolic blood pressure, respectively.

continuous filtration by gravity using a pressure-voltage transducer. Then, $\mathrm{P}$ was transformed to height (h: $\mathrm{mm}$ ). The tangent of the $\mathrm{h}-\mathrm{t}$ curve determined by drawing points corresponding to different heights gives the rate of fall of the meniscus in the vertical tube. Thereafter, by multiplying the fall rate by the internal cross-sectional area of the vertical tube, the complete set of flow rates (Q: $\mathrm{ml} / \mathrm{min})$ and corresponding $\mathrm{P}$ (ie, the $\mathrm{P}-\mathrm{Q}$ relationship) were calculated. This procedure was automatically performed by measurement software installed on a personal computer (Dell Inc, Round Rock, TX, USA). Great care was taken to fill the vertical tube with each suspension without air bubbles. As well as starting the data acquisition process, the measurement software displays the ongoing $\mathrm{h}-\mathrm{t}$ relationship on the computer screen. When the test is completed, the software displays the $\mathrm{P}-\mathrm{Q}$ curve. ${ }^{4}$ The temperature of the specimens was maintained at $25^{\circ} \mathrm{C}$ by circulating isothermal water through a water jacket surrounding the vertical tube (Figure 1). The experiments were performed within $1 \mathrm{~h}$ of preparing the suspensions at room temperature $\left(21 \pm 0.5^{\circ} \mathrm{C}\right)$.

An aliquot of erythrocyte suspension was fixed with isotonic $1.0 \%$ glutaraldehyde solution containing $24.5 \mathrm{mmol} / \mathrm{L}$ $\mathrm{NaCl}$ and $50 \mathrm{mmol} / \mathrm{L}$ phosphate buffer ( $\mathrm{pH} 7.4$ ). The shape of the erythrocytes was then examined using a differential interference contrast microscope (Diaphoto 300, Nikon Co Ltd, Tokyo, Japan) at $\times 400$ magnification.

\section{Data Analysis}

All values are expressed as mean \pm SD. Comparison of data between specific groups ( $n=8-16$ rats/group) was performed by unpaired Student's t-test, because this study did not have repeated comparisons. Microsoft Excel 2003 on Windows XP (Microsoft, Tokyo, Japan) was used for practical computation. A P value $<0.05$ was considered to be significant.

\begin{tabular}{|c|c|c|}
\hline Age (weeks) & SHR & $\begin{array}{c}\text { Age-matched } \\
\text { WKY }\end{array}$ \\
\hline \multicolumn{3}{|c|}{ Leukocyte count $\left(\times 10^{2} / \mu \mathrm{l}\right)$} \\
\hline 7 & $50.4 \pm 7.5^{\star}$ & $29.0 \pm 6.8$ \\
\hline 13 & $50.0 \pm 6.2^{*}$ & $31.9 \pm 3.4$ \\
\hline 18 & $46.6 \pm 8.2$ & $36.2 \pm 12.4$ \\
\hline \multicolumn{3}{|c|}{ Platelet count $\left(\times 10^{4} / \mu \mathrm{I}\right)$} \\
\hline 7 & $117.7 \pm 7.6^{*}$ & $93.1 \pm 14.1$ \\
\hline 13 & $90.1 \pm 5.3^{\# \#, *}$ & $87.8 \pm 7.8$ \\
\hline 18 & $81.3 \pm 4.1^{\# \#}$ & $80.5 \pm 5.5$ \\
\hline \multicolumn{3}{|c|}{ Erythrocyte count $\left(\times 10^{4} / \mu \mathrm{l}\right)$} \\
\hline 7 & $720.3 \pm 17.1^{*}$ & $627.7 \pm 20.7$ \\
\hline 13 & $880.6 \pm 23.9^{\# \#, *}$ & $734.4 \pm 28.8^{\# \#}$ \\
\hline 18 & $913.3 \pm 27.2^{\# \#, *}$ & $755.5 \pm 20.0^{\# \#}$ \\
\hline \multicolumn{3}{|l|}{$\mathrm{Hb}(\mathrm{g} / \mathrm{dl})$} \\
\hline 7 & $13.0 \pm 0.3$ & $12.5 \pm 0.3$ \\
\hline 13 & $14.3 \pm 0.4^{\# \#, \star}$ & $13.5 \pm 0.3^{\#}$ \\
\hline 18 & $14.1 \pm 0.4^{\# \#, *}$ & $12.8 \pm 0.4$ \\
\hline \multicolumn{3}{|l|}{ Het (\%) } \\
\hline 7 & $40.5 \pm 1.1$ & $38.8 \pm 1.4$ \\
\hline 13 & $44.8 \pm 1.1^{\# \#, *}$ & $41.2 \pm 1.4^{\ddagger}$ \\
\hline 18 & $45.1 \pm 1.4^{\# \#, *}$ & $39.9 \pm 1.1$ \\
\hline
\end{tabular}

Values are expressed as mean \pm SD. ${ }^{*} P<0.005$ for age-matched comparison, and $¥ \mathrm{P}<0.01,{ }^{\# P}<0.005$ and $\# \mathrm{P}<0.001$ for comparison between 7 and respective weeks of age within the same strain. $\mathrm{Hb}$ and $\mathrm{Hct}$, hemoglobin concentration $(\mathrm{g} / \mathrm{dl})$ and hematocrit value (\%), respectively. Other abbreviations see in Table 1.

\section{Results}

\section{Baseline Characteristics}

Developmental changes in BP and PR were observed in both SHR and WKY. As shown in Table 1, the systolic, mean and diastolic BP of the SHR rapidly elevated between 7 and 13 weeks of age and then gradually elevated toward 18 weeks, whereas BP rose slightly in young WKY (7-13 weeks of age) as previously reported. ${ }^{13,16}$ Difference in BP between the 2 age-matched strains was significant at 13 and 18 but not at 7 weeks of age. PR in SHR tended to be greater than that in WKY and the PR in both strains decreased gradually with maturation (ie, from 7 to 18 weeks).

\section{Hematology in SHR and WKY}

Leukocyte and platelet counts in the SHR were significantly $(\mathrm{P}<0.005)$ greater than those in the age-matched WKY at 7 and 13 but not 18 weeks of age. With maturation, the platelet count gradually decreased in the SHR $(\mathrm{P}<0.001)$. The erythrocyte count increased with age in both strains $(\mathrm{P}<0.001)$, but was significantly $(\mathrm{P}<0.005)$ greater in the SHR than in the age-matched WKY. Age-matched comparisons of hemoglobin concentration $(\mathrm{g} / \mathrm{dl})$ and hematocrit value $(\%)$ were compatible with these findings (Table 2). Morphologically, erythrocytes obtained from the SHR did not show any discernible changes in shape nor did those from the WKY (data not shown).

\section{Representative P-Q Relationships}

Figure 2 shows representative $\mathrm{P}-\mathrm{Q}$ relationships for the HBS (saline) and several of the erythrocyte suspensions in the continuous filtration experiments. The $\mathrm{P}-\mathrm{Q}$ relationship of saline was linear and passed through the origin, indicating 


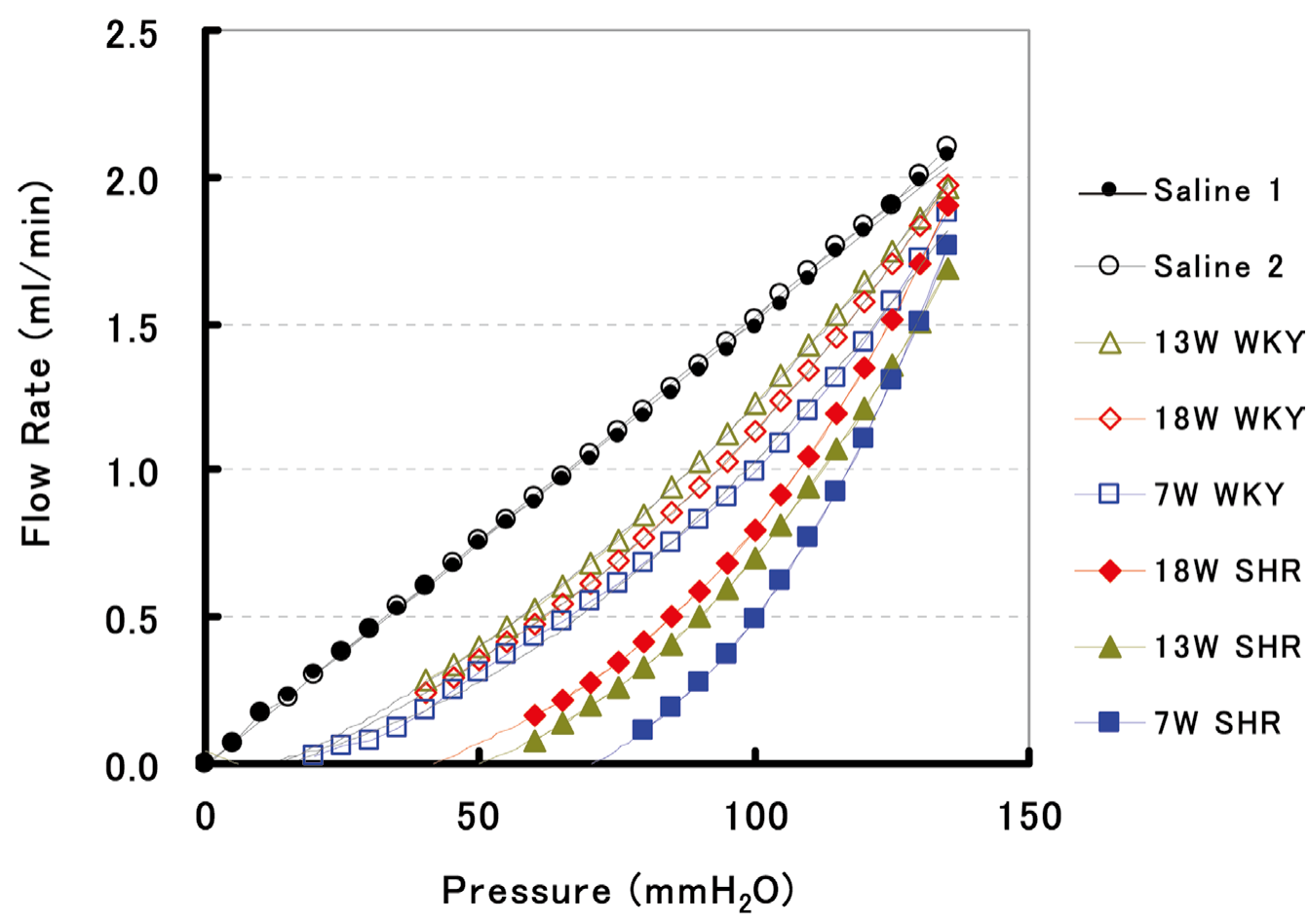

Figure 2. Representative relationships between pressure $\left(\mathrm{P}: \mathrm{mmH}_{2} \mathrm{O}\right)$ and flow rate $(\mathrm{Q}: \mathrm{ml} / \mathrm{min})$ during the continuous filtration experiment. The $\mathrm{P}-\mathrm{Q}$ relationships of HEPES-buffered saline (saline 1: $\bullet, 2$ : $\bigcirc$ ), the erythrocyte suspensions for representative control (normotensive WKY) at 7,13 and 18 weeks of age $(\square, \Delta, \diamond)$ and SHR at the same ages $(\square, \Delta, \diamond)$. The hematocrit value of the erythrocyte suspensions was $2.0 \%$ throughout.

Newtonian behavior of the HBS. Two of the $\mathrm{P}-\mathrm{Q}$ relationships of the HBS were superimposable, showing the excellent reproducibility of this filtration system. In contrast, the $\mathrm{P}-\mathrm{Q}$ relationships of the erythrocyte suspensions displayed smooth convex curves along the abscissa over the low-pressure region, indicating non-Newtonian characteristics of the suspensions. As shown, the flow rate of the erythrocyte suspension from normotensive WKY at 7, 13 and 18 weeks of age was greater than that from SHR at the same ages at any given pressure. These results indicate that the erythrocyte filterability of SHR is impaired compared with agematched controls. The ratio $(\%)$ of the flow rate of the erythrocyte suspension relative to that of the $\mathrm{HBS}$ at $100 \mathrm{mmH}_{2} \mathrm{O}$ was used as an index of erythrocyte filterability.

\section{Erythrocyte Filterability}

Figure 3A shows the mean erythrocyte filterability in SHR and WKY at 7, 13 and 18 weeks of age: it was significantly lower in the SHR $(37.0 \pm 17.5 \%$ at 7 weeks, $52.0 \pm 11.4 \%$ at 13 weeks, $51.6 \pm 13.3 \%$ at 18 weeks) than in the age-matched WKY $(62.1 \pm 7.2 \%$ at 7 weeks: $\mathrm{P}<0.005,76.4 \pm 4.3 \%$ at 13 weeks: $\mathrm{P}<0.005,71.1 \pm 3.9 \%$ at 18 weeks: $\mathrm{P}<0.005)$. In detail, erythrocyte filterability in the SHR showed a significant $(\mathrm{P}<0.005)$ decrease compared with that in the age-matched WKY even in the accelerated (13 weeks) and established (18 weeks) stage of hypertension, as well as in the prehypertensive stage (7 weeks). Figure $\mathbf{3 A}$ also shows that the greatest decrease in filterability of SHR erythrocytes was observed at 7 weeks compared with that at 13 weeks $(\mathrm{P}<0.05)$ and 18 weeks $(\mathrm{P}<0.01)$. Similarly, WKY showed decreased filterability at 7 weeks relative to that at 13 weeks $(\mathrm{P}<0.005)$ and
18 weeks $(\mathrm{P}<0.05)$.

\section{Erythrocyte Characteristics}

Figure 3B shows the mean corpuscular volume (MCV) of erythrocytes from SHR and WKY at 7, 13 and 18 weeks of age: it was significantly smaller in SHR $(56.3 \pm 0.7 \mathrm{fl}$ at 7 weeks, $50.3 \pm 0.3 \mathrm{fl}$ at 13 weeks, $49.3 \pm 0.3 \mathrm{fl}$ at 18 weeks) than in age-matched WKY $(61.9 \pm 2.0 \mathrm{fl}$ at 7 weeks: $\mathrm{P}<0.005$, $56.1 \pm 2.1 \mathrm{fl}$ at 13 weeks: $\mathrm{P}<0.005,52.8 \pm 2.2 \mathrm{fl}$ at 18 weeks: $\mathrm{P}<0.005)$. Figure $3 \mathrm{~B}$ also shows that the greatest $\mathrm{MCV}$ of erythrocytes from SHR was observed at 7 weeks of age compared with that at 13 weeks $(\mathrm{P}<0.005)$ and 18 weeks $(\mathrm{P}<0.005)$. Similarly, WKY showed the greatest MCV of erythrocytes at 7 weeks compared with that at 13 weeks $(\mathrm{P}<0.005)$ and 18 weeks $(\mathrm{P}<0.005)$. It is generally known that the MCV of rat erythrocytes decreases with age, ${ }^{13}$ and this was confirmed by the present study.

Figure 3C shows the mean corpuscular hemoglobin concentration $(\mathrm{MCHC})$ of erythrocytes from the 2 strains of rat at 7, 13 and 18 weeks of age. At 7 weeks of age the MCHC of erythrocytes from SHR was almost the same as that from age-matched WKY $(32.1 \pm 0.3 \mathrm{~g} / \mathrm{dl}$ vs $32.2 \pm 0.4 \mathrm{~g} / \mathrm{dl}$; $\mathrm{P}=0.45$ ), but at 13 and 18 weeks of age it was lower $(31.8 \pm 0.4 \mathrm{~g} / \mathrm{dl}$ at 13 weeks, $31.2 \pm 0.2 \mathrm{~g} / \mathrm{dl}$ at 18 weeks) than that from age-matched WKY $(32.8 \pm 0.4 \mathrm{~g} / \mathrm{dl}$ at 13 weeks: $\mathrm{P}<0.005,32.1 \pm 0.4 \mathrm{~g} / \mathrm{dl}$ at 18 weeks: $\mathrm{P}<0.005)$. Furthermore, Figure $3 \mathrm{C}$ shows that the greatest $\mathrm{MCHC}$ of erythrocytes from SHR was observed at 7 weeks of age compared with that at $13(\mathrm{P}<0.05)$ and $18(\mathrm{P}<0.005)$ weeks of age. 


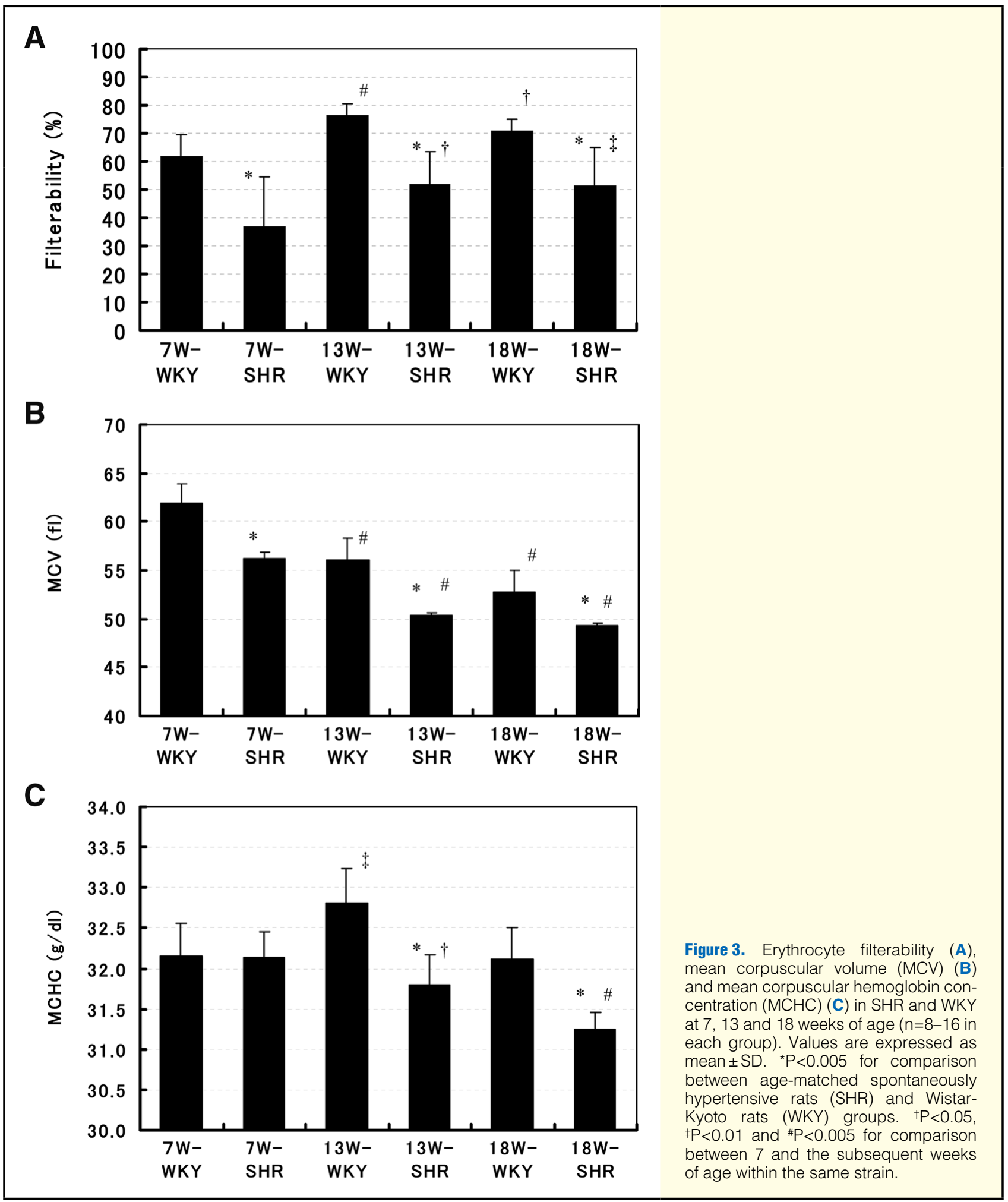

\section{Discussion}

\section{Main Findings}

We investigated quantitatively the hemorheology of SHR and demonstrated clearly that erythrocyte filterability (whole cell deformability) is markedly decreased in SHR in an agedependent manner (Figures 2,3A). Taking the polycythemia of SHR into account (Table 2), the markedly reduced eryth- rocyte filterability will have a great rheologic effect on impairing the microcirculation and increasing microvascular resistance.

\section{Mechanisms of Impaired Filterability}

It is generally accepted that erythrocyte filterability is mainly determined by (1) erythrocyte membrane properties, (2) internal viscosity of the erythrocytes, as reflected by MCHC, 
and (3) geometric factors such as MCV and erythrocyte shape. , $3,5,17$ Therefore, erythrocyte filterability is theoretically reduced by greater MCV or MCHC, abnormal membrane properties and several types of shape change, individually or in concert. MCV in the SHR was smaller than that in the WKY (Figure 3B) and MCHC in the SHR was about the same or lower compared with that in the WKY (Figure 3C). These findings should contribute to improved erythrocyte filterability in SHR. In addition, there were no discernible erythrocyte shape changes in either strain of rat. However, erythrocyte filterability in the SHR was markedly decreased relative to that in WKY (Figures 2,3A). Our findings support strongly the concept that impaired filterability in SHR is mainly attributable to altered erythrocyte membrane properties. In fact, abnormal compositions of erythrocyte membrane protein ${ }^{18,19}$ and phospholipid ${ }^{20}$ have been reported in genetic hypertension of rats, which contributes to reduced erythrocyte membrane fluidity ${ }^{20}$ and increased erythrocyte aggregability. ${ }^{18}$

It is well known that several types of mechanical stress impair erythrocyte filterability through the action of $\mathrm{Ca}^{2+}$ mediated signal transduction; mechanical stress on the erythrocyte membrane causes transmembrane $\mathrm{Ca}^{2+}$ entry and impairs erythrocyte deformability. ${ }^{7,21,22}$ Many investigations have demonstrated that arterial resistance, ${ }^{23,24}$ and hence the blood flow shear rate, ${ }^{25}$ is elevated in young SHR prior to the development of hypertension. Moreover, the erythrocyte free $\mathrm{Ca}^{2+}$ concentration and transmembrane $\mathrm{Ca}^{2+}$ influx are increased in SHR relative to WKY. ${ }^{26}$ Therefore, it is likely that in SHR the accelerated vasoconstriction mechanically stresses the circulating erythrocytes and subsequently impairs their filterability through a $\mathrm{Ca}^{2+}$-mediated signaling pathway, which may further increase microvascular resistance. In the present study, mechanical damage to erythrocytes exposed to continuous high shear stress might have offset and overcome the favorable outcome of MCV and MCHC (Figures 3B, C) and markedly impaired erythrocyte filterability in the SHR.

Although controversy exists, ${ }^{27}$ morphological vascular changes are reported in established hypertension of SHR;16 that is, persistent vasoconstriction induces vascular remodeling such as luminal narrowing and intimal thickening of terminal arterioles (inward remodeling). Contrarily, adaptation may occur to maintain normal luminal diameter and physiological shear rates in resistance vessels by means of shear-induced vascular dilatation (ie, outward remodeling). Reportedly, the shear rate of arterioles is elevated in young SHR, but reduced to a level lower than that of age-matched WKY in mature SHR. ${ }^{25}$ These findings indicate that outward remodeling compensates for the augmented blood flow shear stress in established hypertension, which may explain the attenuated impairment of erythrocyte filterability in mature SHR (Figure 3A).

Recently, oxidative stress was known to play an etiological role in genetic hypertension. SHR show elevated vascular production of and sensitivity to the superoxide $\left(\mathrm{O}_{2}{ }^{-}\right)$ anion. ${ }^{28,29}$ Actually, NADH/NADPH oxidase plays a major role in $\mathrm{O}_{2}{ }^{--}$generation, ${ }^{30,31}$ and $\mathrm{O}_{2}{ }^{--}$dismutase mimetic compound is reported to normalize high BP in genetically hypertensive rats. ${ }^{32,33}$ SHR are reported to show augmented susceptibility of blood to oxidative stress ${ }^{34}$ which causes not only endothelial dysfunction but also impaired erythrocyte filterability. Our previous study using nickel mesh filtration demonstrated that oxidative stress impairs intact human erythrocyte filterability in vitro in a dose-dependent manner. ${ }^{35,36}$
Oxidative stress induces progressive protein degradation and phospholipid peroxidation of the erythrocyte membrane, leading to impairment of membrane fluidity. Because the antioxidative capacity against $\mathrm{O}_{2}{ }^{-}$is diminished in aged genetically hypertensive rats, ${ }^{37}$ sustained impairment of erythrocyte filterability (Figure 3A) may be explained in part by low-grade but persistent oxidative stress and reduced antioxidative capacity in mature SHR.

\section{Prior Studies}

Rheologic assessment of erythrocyte deformability uses 3 major methodologies: filtration experiments, micropipette techniques and ectacytometry. Previous reports regarding erythrocyte rheology in SHR are limited and the results are diverse. ${ }^{13,15}$ The erythrocyte has a lifespan of approximately 120 days and deformability depends on its age. Micropipette techniques deal with individual erythrocytes of unknown age, so can not obtain rheologic information with respect to a population of erythrocytes of different ages. This technique has clarified a significant increase in erythrocyte membrane elasticity at an early, but not a late, stage of hypertension in SHR, ${ }^{13}$ which may be related in part to the limited reproducibility. Ectacytometry has demonstrated that impaired erythrocyte deformability is based on elevated internal viscosity, not on increased membrane rigidity, in SHR ${ }^{15}$ However, this method quantifies erythrocyte elongation, which is not relevant to physiological erythrocyte deformation within microvessels and is associated with limited sensitivity. Filtration experiments, on the other hand, are practical, the nickel mesh has ideal filter properties (Figure 1B), and data analysis is based on the $\mathrm{P}-\mathrm{Q}$ curve (Figure 2), a fundamental relationship in circulatory physiology..$^{2,3}$ In addition, the methodology provides highly sensitive, reproducible and quantitative data allowing analysis of signal transduction within erythrocytes, ${ }^{7}$ although further improvement is required to adjust the erythrocyte number instead of the hematocrit value in suspensions.

\section{Clinical Implications}

Hypertensive patients showing elevated inflammatory markers demonstrate a higher prevalence of target organ damage. ${ }^{38}$ Moreover, absolute peripheral blood flow is reduced in human hypertension ${ }^{39}$ because of high blood viscosity ${ }^{40}$ and abnormal erythrocyte rheology, such as reduced membrane fluidity, ${ }^{41}$ and an elevated erythrocyte free $\mathrm{Ca}^{2+}$ concentration. ${ }^{42}$ This line of evidence implies that circulating erythrocytes of hypertensive patients experience persistent inflammatory damage and shear stress, which impairs erythrocyte filterability by signal transduction involving intracellular $\mathrm{Ca}^{2+}$. This can affect the blood's rheologic properties and the interaction of erythrocytes and resistance vessels, contributing to the elevation in flow resistance and BP. We found that prostaglandin $E_{1}$, an activator of adenylate cyclase, and xanthine derivatives, such as pentoxifylin, a potent inhibitor of phosphodiesterase, markedly improve mechanically impaired erythrocyte filterability. ${ }^{7}$ Thus, modulation of the intracellular $\mathrm{Ca}^{2+}$ - and cAMP-mediated signaling pathways that regulate erythrocyte filterability may be a unique therapeutic strategy against clinical hypertension.

\section{Study Limitations}

In the present study, 2 determinants of BP, cardiac output and vascular resistance, were not evaluated and redox status was not estimated during the development of hypertension in the SHR. These limitations made the mechanisms of impaired 
erythrocyte filterability obscure. However, developmental changes in the vascular tonus of SHR have been reported ${ }^{23-25}$ and the role of oxidative stress in genetic hypertension is evident in the literature. ${ }^{28-34}$ Accordingly, the interpretation of the present data is not contradictory to the outcome of those investigations. However, the present findings can not be extrapolated directly to clinical hypertension, despite SHR being an excellent model of human hypertension. ${ }^{9,10}$

\section{Conclusions}

We demonstrated that SHR show a marked decrease in erythrocyte filterability when compared with age-matched WKY, using a highly sensitive and quantitative nickel mesh filtration technique (ie, it was greatest in young SHR and sustained in mature SHR). Although age-dependent vascular tonus and redox status were not explored, the marked and sustained decrease of erythrocyte filterability in the SHR could not be explained by MCV and MCHC and is considered to be caused by erythrocyte membrane abnormalities. ${ }^{11-13}$ Thus, markedly impaired erythrocyte filterability, in addition to polycythemia, contributes to the development and maintenance of hypertension in SHR.

\section{Acknowledgments}

We thank Tomomi Nakashima, Aya Satoh and Yukiko Uno, staff at the Institute of Rheological Function of Foods Co Ltd, for their excellent technical assistance. This study was supported by a Grant-In-Aid from the Japanese Ministry of Education, Culture, Sports, Science and Technology (18500328).

\section{Disclosure}

The authors report no conflicts of interest.

\section{References}

1. Levy BI, Schiffrin EL, Mourad JJ, Agostini D, Vicaut E, Safar ME, et al. Impaired tissue perfusion: A pathology common to hypertension, obesity, and diabetes mellitus. Circulation 2008; 118: $968-$ 976.

2. Arai K, Iino M, Shio H, Uyesaka N. Further investigations of red cell deformability with nickel mesh. Biorheology 1990; 27: 47-65.

3. Nakamura T, Hasegawa S, Shio H, Uyesaka N. Rheologic and pathophysiologic significance of red cell passage through narrow pores. Blood Cells 1994; 20: 151-165.

4. Ohnishi Y, Fujino T, Satoh A, Takeda S, Harada M, Uyesaka N, et al. Effects of oligomeric procyanidins (OPCs) on human erythrocyte filterability and microcirculation. J Jpn Soc Biorheol 2005; 19: $83-92$.

5. Hiruma H, Noguchi CT, Uyesaka N, Schechter AN, Rodgers GP. Contributions of sickle hemoglobin polymer and sickle cell membranes to impaired filterability. Am J Physiol 1995; 268: H2003H2008.

6. Rodgers GP, Dover GJ, Uyesaka N, Noguchi CT, Schechter AN, Nienhuis AW. Augmentation by erythropoietin of the fetal-hemoglobin response to hydroxyurea in sickle cell disease. $N$ Engl $J$ Med 1993; 328: 73-80.

7. Oonishi T, Sakashita K, Uyesaka N. Regulation of red blood cell filterability by $\mathrm{Ca}^{2+}$ influx and cAMP-mediated signaling pathways. Am J Physiol 1997; 273: C1828-C1834.

8. Fahraeus R, Lindqvist T. The viscosity of the blood in narrow capillary tubes. Am J Physiol 1931; 96: 562-568.

9. Mori T, Nishimura H, Ueyama M, Kubota J, Kawamura K. Comparable effects of angiotensin II and converting enzyme blockade on hemodynamics and cardiac hypertrophy in spontaneously hypertensive rats. Jpn Circ J 1995; 59: 624-630.

10. Arata Y, Geshi E, Nomizo A, Aoki S, Katagiri T. Alterations in sarcoplasmic reticulum and angiotensin II receptor type 1 gene expression in spontaneously hypertensive rat hearts. Jpn Circ J 1999; 63: 367-372.

11. Aragon-Birlouez I, Montenay-Garestier T, Devynck MA. Further analysis of cell membrane changes in genetic hypertension in rats by diphenylexatriene fluorescence polarization. Clin Sci 1984; 66:
717-723.

12. Pezeshk A, Dalhouse AD. Vitamin E, membrane fluidity, and blood pressure in hypertensive and normotensive rats. Life Sci 2000; 67: $1881-1889$.

13. Chabanel A, Schachter D, Chien S. Increased rigidity of red blood cell membrane in young spontaneously hypertensive rats. Hypertension 1987; 10: 603-607.

14. Seki J. Flow pulsation and network structure in mesenteric microvasculature of rats. Am J Physiol 1994; 266: H811-H821.

15. Katiukhin LN. Ectacytometry of the erythrocytes in rats of the SHR, WKY and Wistar strains. Zh Evol Biokhim Fiziol 1994; 30: 232-237 (in Russian with English abstract).

16. Limas C, Westrum B, Limas CJ. The evolution of vascular changes in the spontaneously hypertensive rat. Am J Pathol 1980; 98: $357-$ 384.

17. Mohandas N, Chasis JA. Red cell deformability, membrane material properties and shape: Regulation by transmembrane, skeletal and cytosolic proteins and lipids. Semin Hematol 1993; 30: $171-$ 192.

18. Lominadze D, Schuschke DA, Joshua IG, Dean WL. Increased ability of erythroytes to aggregate in spontaneously hypertensive rats. Clin Exp Hypertens 2002; 24: 397-406.

19. Gulak PV, Orlov SN, Postnov YV. Investigation of membrane proteins in rat erythrocytes in spontaneous hypertension by means of spin-label technique. J Hypertension 1986; 4: 313-317.

20. Dorrance AM, Graham D, Webb RC, Fraser R, Dominiczak A. Increased membrane sphingomyelin and arachidonic acid in strokeprone spontaneously hypertensive rats. Am J Hypertens 2001; 14: $1149-1153$

21. Johnson RM, Tang $\mathrm{K}$. Induction of $\mathrm{Ca}^{2+}$-activated $\mathrm{K}^{+}$channel in human erythrocytes by mechanical stress. Biochim Biophys Acta 1992; 1107: $314-318$.

22. O'Rear EA, Udden MM, Farmer JA, McIntire LV, Lynch EC. Increased intracellular calcium and decreased deformability of erythrocytes from prosthetic heart valve patients. Clin Hemorheol 1984; 4: 461-471.

23. Shibuya J, Ohyanagi M, Iwasaki T. Enhanced myogenic response in resistance small arteries from spontaneously hypertensive rats: Relationship to the voltage-dependent calcium channel. Am J Hypertens 1998; 11: 767-773.

24. Hughes JM, Bund SJ. Arterial myogenic properties of the spontaneously hypertensive rat. Exp Physiol 2002; 87: 527-534.

25. Lominadze D, Joshua IG, Schuschke DA. Blood flow shear rates in arterioles of spontaneously hypertensive rats at early and established stages of hypertension. Clin Exp Hypertens 2001; 23: 317 328.

26. David-Dufilho M, Pernollet MG, Morris M, Astarie-Dekequer C, Devynck MA. Erythrocyte $\mathrm{Ca}^{2+}$ handling in the spontaneously hypertensive rat, effect of vanadate ions. Life Sci 1994; 54: $267-$ 274.

27. Yuan YV, Kitts DD, Godin DV. Heart and red blood cell antioxidant status and plasma lipid levels in the spontaneously hypertensive and normotensive Wistar-Kyoto rat. Can J Physiol Pharmacol 1996; 74: 290-297.

28. Auch-Schwelk W, Katusie ZS, Vanhoutte PM. Contractions to oxygen-derived free radicals are augmented in aorta of the spontaneously hypertensive rat. Hypertension 1989; 13: 859-864.

29. Suzuki H, Swei A, Zweifach BW, Schmid-Schönbein GW. In vivo evidence for microvascular oxidative stress in spontaneously hypertensive rats. Hypertension 1995; 25: 1083-1089.

30. Zalba G, José GS, Moreno MU, Fortuño MA, Fortuño A, Beaumont FJ, et al. Oxidative stress in arterial hypertension: Role of NAD(P)H oxidase. Hypertension 2001; 38: 1395-1399.

31. Landmesser U, Cai H, Dikalov S, McCann L, Hwang J, Jo H, et al. Role of p47(phox) in vascular oxidative stress and hypertension caused by angiotensin II. Hypertension 2002; 40: 511-515.

32. Schnakenberg CG, Welch WJ, Wilcox CS. Normalization of blood pressure and renal vascular resistance in SHR with a membranepermeable superoxide dismutase mimetic. Hypertension 1998; 32: $59-64$

33. Park JB, Touyz RM, Chen X, Schiffrin EL. Chronic treatment with a superoxide dismutase mimetic prevents vascular remodeling and progression of hypertension in salt-loaded stroke-prone spontaneously hypertensive rats. Am J Hypertens 2002; 15: 78-84.

34. Friedman J, Peleg E, Kagan T, Shnizer S, Rosenthal T. Oxidative stress in hypertensive, diabetic, and diabetic hypertensive rats. Am J Hypertens 2003; 16: 1049-1052.

35. Uyesaka N, Hasegawa S, Ishioka N, Ishioka R, Shio H, Schechter AN. Effects of superoxide anions on red cell deformability and membrane proteins. Biorheology 1992; 29: 217-229. 
36. Okamoto K, Maruyama T, Kaji Y, Harada M, Mawatari S, Fujino $\mathrm{T}$, et al. Verapamil prevents impairment in filterability of human erythrocytes exposed to oxidative stress. Jpn J Physiol 2004; 54: $39-46$.

37. Kimoto-Kinoshita S, Nishida S, Tomura TT. Age-related changes of antioxidant capacities in the cerebral cortex and hippocampus of stroke-prone spontaneously hypertensive rats. Neurosci Lett 1999; 273: $41-44$.

38. Kim KI, Lee JH, Chang HJ, Cho YS, Youn TJ, Chung WY, et al. Association between blood pressure variability and inflammatory marker in hypertensive patients. Circ J 2008; 72: 293-298.

39. Kura N, Fujikawa T, Tochikubo O. New finger-occlusion plethys- mograph for estimating peripheral blood flow and vascular resistance. Circ J 2008; 72: 1329-1335.

40. Letcher RL, Chien S, Pickering TG, Laragh JH. Elevated blood viscosity in patients with borderline essential hypertension. Hypertension 1983; 5: 757-762.

41. Tsuda K, Kimura K, Nishio I, Masuyama Y. Nitric oxide improves membrane fluidity of erythrocyte in essential hypertension: An electron paramagnetic resonance investigation. Biochem Biophys Res Commun 2000; 275: 946-954.

42. David-Dufilho M, Astarie C, Pernollet MG, Del Pino M, Levenson $\mathrm{J}$, Simon A, et al. Control of the erythrocyte free $\mathrm{Ca}^{2+}$ concentration in essential hypertension. Hypertension 1992; 19: 167-174. 